\title{
Clinical Research out of Insulin Glargine U300 basal bolus therapy and Insulin Degludec/Aspart Co-Formulation in Type 2 Diabetes Mellitus: A Real World Experience
}

savas volkan Kisioglu ${ }^{1}$, Ahmet Suat Demir ${ }^{2}$, damla tufekci², Yasemin Emur Gunay ${ }^{2}$, Hulya Coskun $^{2}$, Ozge Ucuncu ${ }^{2}$, Irfan Nuhoglu², Mustafa Kocak ${ }^{2}$, Serdar Karakullukcu ${ }^{2}$, and Halil Onder ERSOZ ${ }^{2}$

${ }^{1}$ Trabzon Training and Research Hospital

${ }^{2}$ Affiliation not available

January 9, 2021

\begin{abstract}
Aims/Introduction: Insulin Degludec/Aspart (IDegAsp) and Insulin Glargine U300 (IGlarU300) have recently emerged as popular new-generation insulin analogs. The aim of this real-life study was to investigate the patient profiles in which IGlarU300 and IDegAsp were preferred and the insulin combinations after which each of them were mostly used, and also to analyze the effect of these two insulin analogs on blood glucose regulation and hypoglycemia. Materials and Methods: The retrospective study included 174 patients that were switched from basal insulin, basal+bolus insulin, or premixed insulin to IGlarU300 or IDegAsp due to uncontrolled blood glucose levels or history of hypoglycemia. Hypoglycemia, body weight, body mass index (BMI), fasting blood glucose (FBG), and HbA1c levels over three-month periods were evaluated for each patient. Results: There were 84 and 90 patients in the IGlarU300 and IDegAsp groups, respectively. Body weight was similar in both groups. Baseline FBG and HbA1c levels in the IGlarU300 and IDegAsp groups were 9.0\%, $175.5 \mathrm{mg} / \mathrm{dl}$ and 9.4\%, 193.5 mg/dl, respectively. A significant decrease was found in FBG and HbA1c levels in both groups (138.5, 7.8 vs. 141.5, 8.2; p<0.001 for all). Moreover, a significant weight gain was observed in both groups $(\mathrm{p}<0.05$ for both). The prevalence of hypoglycemia in both groups decreased significantly and consistently between month 1 and $9(\mathrm{p}<0.001)$. At month 12 , although this decrease continued in the IGlarU300 group ( $\mathrm{p}=0.013)$, no significant decrease was observed in the IDegAsp group( $\mathrm{p}=0.057)$. Conclusion: Both twice-daily IDegAsp \pm bolus insulin and IGlarU300+bolus insulin therapies are effective and safe treatment modalities.
\end{abstract}

\section{Hosted file}

Manuscript - SK.pdf available at https://authorea.com/users/388395/articles/503210-clinicalresearch-out-of-insulin-glargine-u300-basal-bolus-therapy-and-insulin-degludec-aspartco-formulation-in-type-2-diabetes-mellitus-a-real-world-experience 


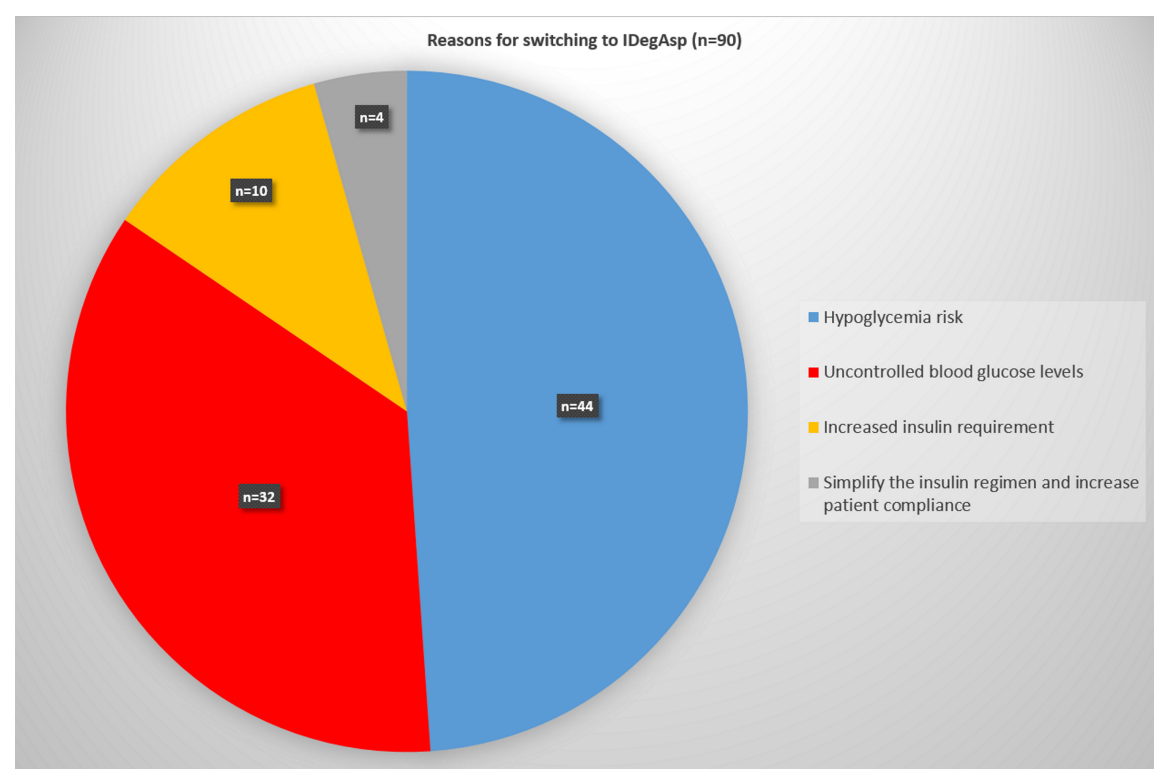

Reasons for switching to IGlarU300

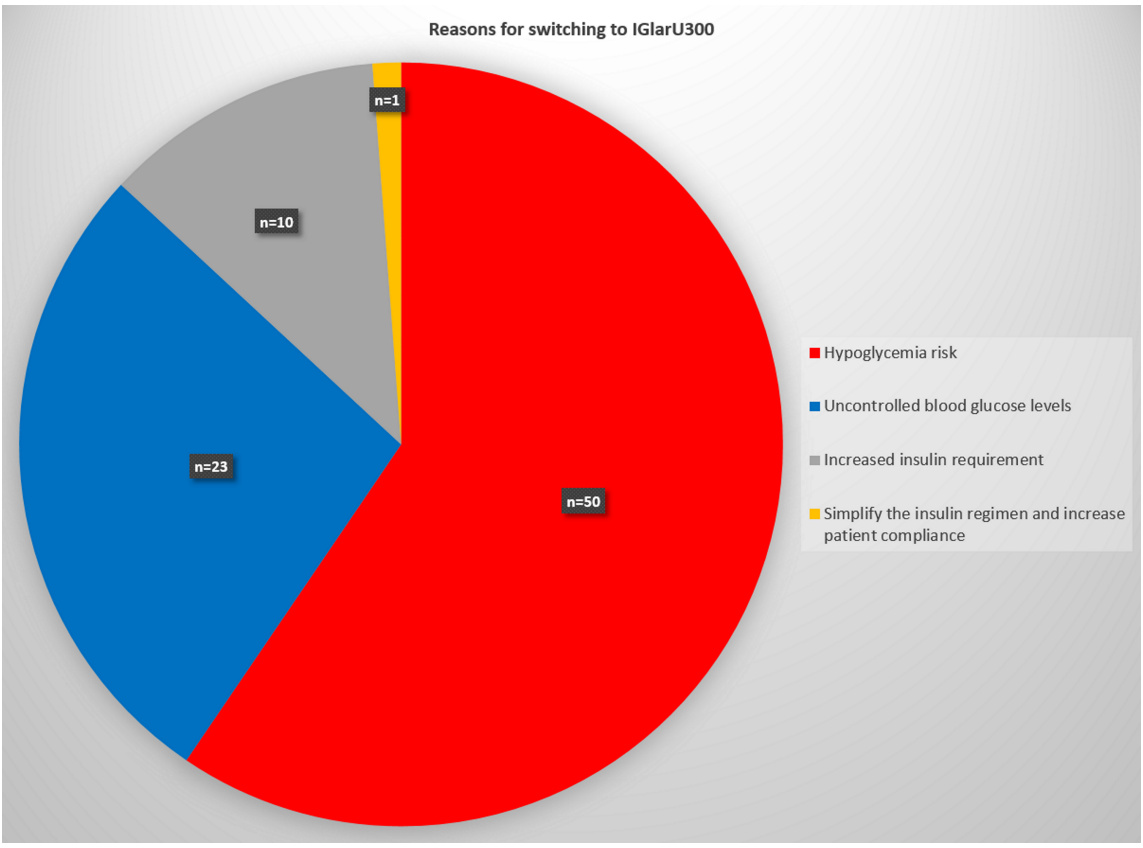



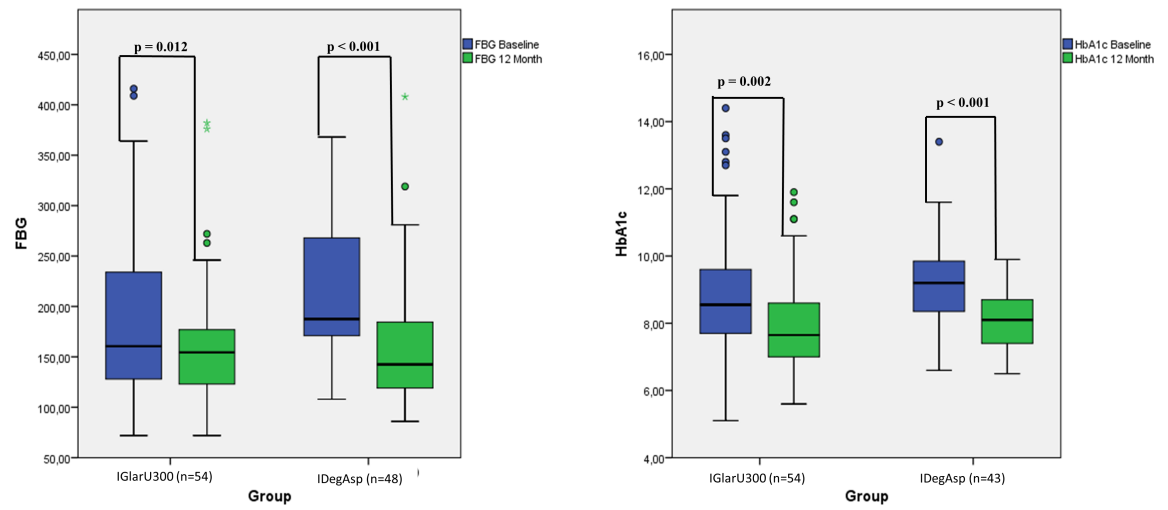